\title{
Improvements in marble protection by means of innovative photocatalytic
} nanocomposites

\author{
F. Gherardi ${ }^{\mathrm{a}^{*}}$, S. Goidanich ${ }^{\mathrm{a}}$, L. Toniolo ${ }^{\mathrm{a}}$
}

${ }^{a}$ Politecnico di Milano, Department of Chemistry, Materials and Chemical Engineering “Giulio Natta”, Piazza Leonardo da Vinci 32, 20133, Milan, Italy

*Corrisponding Author - Email: francesca.gherardi@polimi.it; Phone: +390223993143

\section{Graphical abstract}

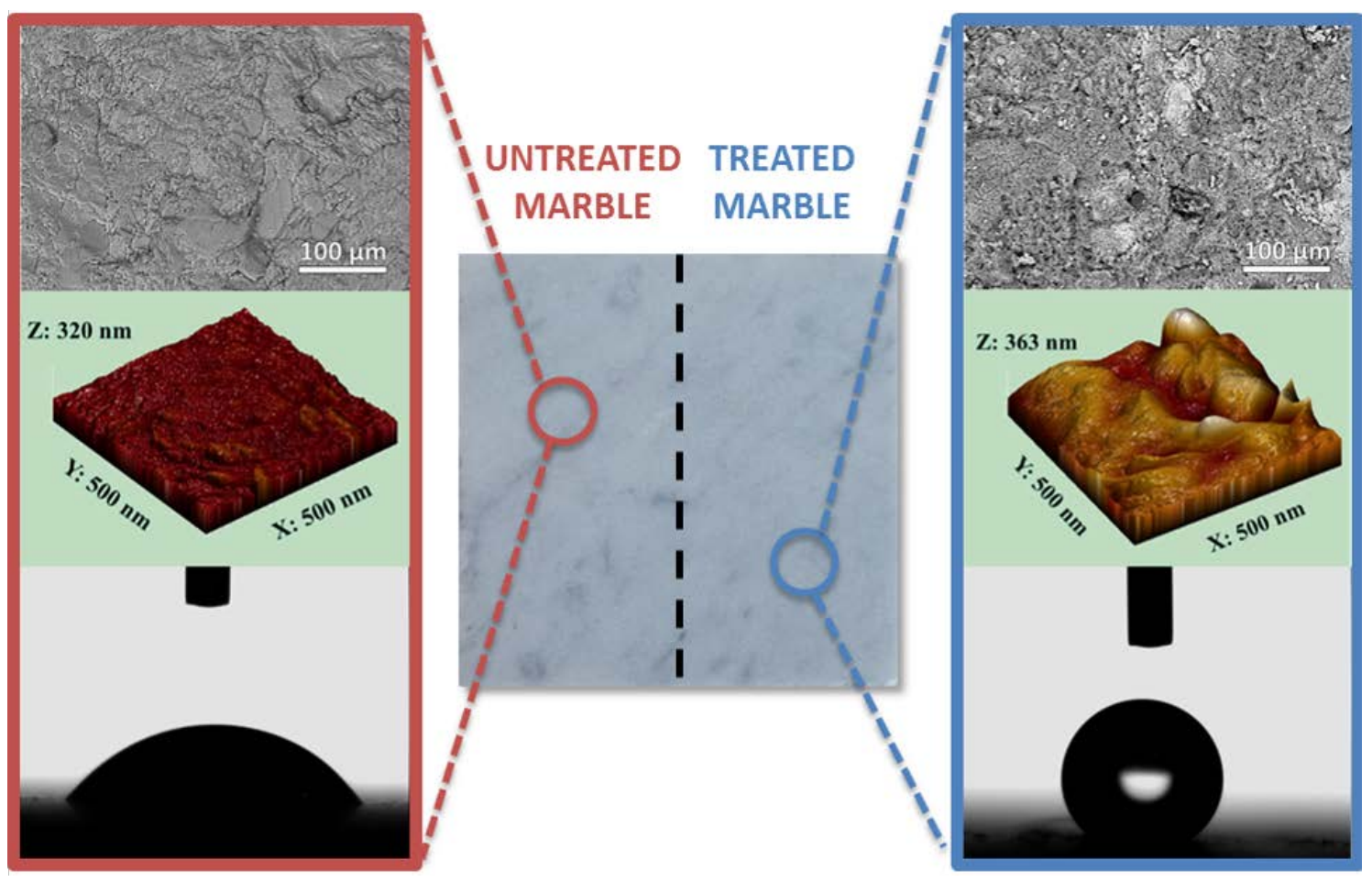

\section{Abstract}

The application of photocatalytic and self-cleaning nanomaterials in the field of architectural heritage is an encouraging strategy for stone conservation and particularly for marble architectural elements. In the present research, self-cleaning nanocomposites were set-up by mixing water dispersions of $\mathrm{TiO}_{2}$ nanoparticles in commercial protective treatments based on organosiloxanes, fluoropolyethers and functionalized $\mathrm{SiO}_{2}$. The pure anatase phase nanoparticles used for their preparation are photoactive under solar light, in addition to UV radiation, due to their benzyl surface capping resulting in an increase of their efficiency in the degradation of pollutants. The nanomaterials applied on Carrara marble specimens show better performance in terms of surface colour compatibility and water repellency compared to traditional protective products. Actually, 
the introduction of nano- $\mathrm{TiO}_{2}$ plays a role in the increase of the surface roughness, with a consequent reduction of the surface wettability. The promising results obtained so far in the lab have also been confirmed on-site on real surfaces of the marble façade of a renaissance cathedral.

Keywords: Stone protection, Self-cleaning, Photocatalytic, Hydrophobic, $\mathrm{TiO}_{2}$-nanocomposites, Marble

\section{Introduction}

Two main classes of protective treatments have been used in the field of stone conservation aiming at reducing the impact of pollution on the rapid degradation of limestones and marbles since the mid-20 ${ }^{\text {th }}$ century. The first wide class is the one of synthetic polymeric materials (acrylic, partially fluorinated and perfluoropolymers, alkyl silicon products) which are able to turn the partial hydrophilic properties of the stone into water-repellent surfaces and the second one includes low molecular weight inorganic products (silica sols and ammonium oxalate) [1-3]. Many studies proved that an "all-purpose” protective product suitable for all lithotypes does not exist as far as different factors influence the performance of a water repellent treatment: the chemical nature and formulation of the product (composition, solvent, concentration, water-emulsion, additives, catalyst, etc.), the mineralogical features, morphology, open porosity and state of conservation of the stone substrate, the application method (by brush, by spray, by absorption) and therefore the penetration depth of the treatment [1]. To find an effective strategy for the protection of low porosity stones, such as marbles, is particularly difficult, due to the poor penetration of the treatments into the substrate, which prevents the good coverage and adhesion of the products to the crystal grains, compromising their effectiveness. In addition, the accumulation of the product on the surface makes it more prone to chemical, thermal, photochemical and mechanical stress, with consequent faster deterioration [2].

Therefore, in the last decade, the scientific research has been devoted to developing innovative surface treatments for the protection of exterior stone surfaces of historic buildings. A diffused strategy is the introduction of nanoparticles inside a polymeric matrix, in order to increase the surface roughness without changing the main characteristics of the material, such as permeability and transparency, and the substrate morphology. When the treated surfaces are exposed to rainfall and humidity, water spherical droplets can easily absorb dust and dirt and roll away, giving rise to the so called "self-cleaning” behaviour [4]. The increase of the water-repellency of the surface is due to the formation of micro-nano binary structures which enhance the surface roughness and reduce the real contact between the liquid water and the stone material. As a result, hydrophobic 
or super-hydrophobic (static contact angle with water $>150^{\circ}$ ) surfaces are obtained. Polymeric water dispersions have been modified by adding different nanoparticles $\left(\mathrm{SiO}_{2}, \mathrm{SnO}_{2}, \mathrm{Al}_{2} \mathrm{O}_{3}, \mathrm{TiO}_{2}\right)$ with the aim of developing surface coatings for natural stones [5-9].

Since 1990s titania nanoparticles have been used, thanks to their photocatalytic properties, in addition to traditional building materials such as concrete, cement mortar, ceramic tiles, paints, glass and PVC fabric [10-12]. In recent years, nano- $\mathrm{TiO}_{2}$ has been also tested in the field of cultural heritage conservation, in particular for the development of photocatalytic and antifouling treatments for stone substrates [13]. When irradiated with photons having energy higher than their band-gap, titania nanoparticles are able to oxidize and decompose organic and inorganic compounds in contact with their surface, generating non-harmful products that can also be easily removed by rainfall $[10,14]$. In addition to the photocatalytic activity, some nano- $\mathrm{TiO}_{2}$ treatments show antifouling properties and are able to prevent biological growth [15-17]. Titania nanoparticles have been used in forms of water or solvent dispersions and applied by brush or by spray directly on the surface of different natural stones (limestones, marble, calcarenite, travertine), making them hydrophilic or superhydrophilic [18-20]. The main limit of these dispersions is that nanoparticles show poor adhesion to stone surfaces and are easily removed by rainfall, or they penetrate into the stone porosity, significantly compromising their photocatalytic activity [21]. A strategy to overcome this issue and avoid the release of nanoparticles in the environment is their introduction in either organic or inorganic matrix [16, 21-23]. Different types of $\mathrm{TiO}_{2}$ nanoparticles have been mixed with polymeric matrix used for the protection of stone surfaces such as alkyl silicon products [8, 21, 24-28], fluorinated or partially fluorinated [29, 30] or acrylic [15, 30, 31] polymers.

A critical issue in the development of nano- $\mathrm{TiO}_{2}$ based treatments is their poor photoactivity under solar light irradiation, since $\mathrm{TiO}_{2}$ based nanomaterials present wide band-gaps, mainly adsorbing ultraviolet photons while solar light only contains a small fraction of ultraviolet photons (about $5 \%$ ). For this reason, the scientific research aims at improving the photocatalytic efficiency of $\mathrm{TiO}_{2}$ under solar light irradiation, by means of morphological modifications such as the increase of surface area and porosity, or chemical modifications with incorporation of dopants in the $\mathrm{TiO}_{2}$ structure to reduce the band-gap and extend the spectral sensitivity from UV to visible light [11, 32].

In the present research, the set-up of different organic nanocomposites is proposed, starting from commercial stone protective treatments which were improved by the addition of innovative $\mathrm{TiO}_{2}$ nanoparticles. The latter are characterized by a surface capping of benzyl alcohol molecules anchored on their surfaces, which make the nanoparticles photoactive even if exposed to solar 
irradiation, increasing their photoefficiency [33]. In addition, as previously reported, the proposed nanocrystals allow to obtain highly stable dispersions in aqueous systems, without affecting the surface colour of the stone substrate [34]. The laboratory experimental work allowed to assess the effectiveness of nanocomposites as protective and self-cleaning treatments for a low porosity stone substrate such as Carrara marble. This stone is mainly composed of regular small size calcite grains, with an average open porosity ranging from 0.5 to $1.0 \%$ and it is, therefore, quite difficult to protect. The pores are arising from the reduced intergranular space, which can be enhanced near the surface by deterioration phenomena [35] and are permeable to aggressive gaseous pollutants and corrosive water solutions, but difficult to cover with water repellent treatments. This study accounts for the challenge to address the critical issues for marble protection.

A thorough comparison between the behaviour of the different treatments before and after the addition of nano- $\mathrm{TiO}_{2}$, has been carried out and discussed.

\section{Materials and Methods}

\subsection{Preparation of $\mathrm{TiO}_{2}$-based nanocomposites and their application on marble specimens}

Nanocomposites were set-up by adding water dispersion of nano- $\mathrm{TiO}_{2}$ to commercial protective treatments used in the conservation field for stone protection. In particular, transparent water dispersion of $\mathrm{TiO}_{2}$ nanoparticles ( $3 \%$ by weight, nanoparticles size around $40 \mathrm{~nm}$ ), synthesized according to the non-aqueous route [36], as reported in previous papers [34, 37], were used for the preparation of the nanocomposites. The nanoparticles show photoactivity in the visible spectral range in addition to UV, due to the residual presence of benzyl alcohol group on the surface of the nanoparticles, deriving from the synthesis.

The selected commercial products for stone materials are: an aqueous dispersion of organosiloxanes (10\% by weight) (Silo 112, CTS srl, labelled as S), an aqueous dispersion of fluoropolyethers (10\% by weight) (Fluoline PE, CTS srl, labelled as F) and a solution of $\mathrm{SiO}_{2}$ functionalized by silicon alcoxides in isopropyl alcohol (20\% by weight) (SIOX-5 S, Siltea srl, labelled as FS). S and F [29, 38] have been chosen as they are products widely used in the field of stone conservation; FS is a promising inorganic protective treatment obtained by sol-gel process from an Italian spin-off company (Siltea srl, Italy).

Nanocomposites were prepared by adding, upon stirring, different amount of water dispersion of nanoparticles to the commercial products as sold, without any further dilution. The obtained composites are reported in Table 1. In particular, adding the nanoparticle (n) dispersion to the polysiloxane-based treatment (Silo 112, S), three different emulsions were obtained, labelled Sn16, 
118 Sn28 and Sn44, showing the following concentrations of nanoparticles in the polymer by weight:

$11916 \%, 28 \%$ and $44 \%$, respectively.

120 For both fluoropolyethers-based (Fluoline $\mathrm{PE}$ ) and functionalized $\mathrm{SiO}_{2}$-based treatments (SIOX-5

$121 S$ ), only one composite was obtained, with a 16\% by weight nanoparticle concentration (labelled

122 Fn16 and FSn16, respectively), since the addition of higher amount of nanoparticles did not grant

123 the preparation of stable composites.

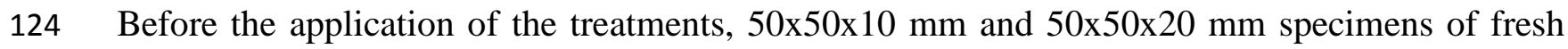

125 Carrara marble were prepared by smoothing their surface with abrasive carborundum paper (Nr.

126 180), washing with deionized water and drying for $48 \mathrm{~h}$ at room temperature until constant weight

127 was achieved. They were finally stored in silica gel desiccator at 55\% UR.

128 The nanocomposites were, then, applied following one single brush application, wetting 129 completely the marble surface (about $25 \mathrm{~cm}^{2}$ ) with the product. The amount of adsorbed dry matter 130 was measured after drying and the values are reported in Table 1 . The variations in the values of 131 average amount of dry matter can be ascribed to differences in the density of the products, and in 132 their ability to homogenously cover the stone surfaces. Untreated stone specimens (labelled NT) were also tested for comparison. 
Table 1. Values of average dry matter (g) of products applied by brush on stone specimens with a 148 surface area of about $25 \mathrm{~cm}^{2}$.

\begin{tabular}{|c|c|c|}
\hline Treatment & Description & Amount of product (g) \\
\hline S & $\begin{array}{l}\text { Commercial polysiloxane } \\
\text { Silo } 112\end{array}$ & $0.06 \pm 0.01$ \\
\hline $\operatorname{Sn} 16$ & $\begin{array}{c}\text { nanocomposite based on } \\
\text { polysiloxane Silo } 112 \text { with } \\
\text { nano- } \mathrm{TiO}_{2}(16 \mathrm{wt} \%)\end{array}$ & $0.12 \pm 0.01$ \\
\hline $\operatorname{Sn} 28$ & $\begin{array}{c}\text { nanocomposite based on } \\
\text { polysiloxane Silo } 112 \text { with } \\
\text { nano- } \mathrm{TiO}_{2}(28 \mathrm{wt} \%)\end{array}$ & $0.14 \pm 0.01$ \\
\hline $\operatorname{Sn} 44$ & $\begin{array}{c}\text { nanocomposite based on } \\
\text { polysiloxane Silo } 112 \text { with } \\
\text { nano- } \mathrm{TiO}_{2}(44 \mathrm{wt} \%)\end{array}$ & $0.14 \pm 0.01$ \\
\hline $\mathbf{F}$ & $\begin{array}{l}\text { Commercial fluoropolyethers } \\
\text { Fluoline PE }\end{array}$ & $0.08 \pm 0.01$ \\
\hline Fn16 & $\begin{array}{c}\text { nanocomposite based on } \\
\text { fluoropolyethers Fluoline PE } \\
\text { with nano- } \mathrm{TiO}_{2}(16 \mathrm{wt} \%)\end{array}$ & $0.10 \pm 0.01$ \\
\hline FS & $\begin{array}{c}\text { Commercial functionalized } \\
\mathrm{SiO}_{2} \mathrm{SIOX}_{-5} \mathrm{~S}\end{array}$ & $0.02 \pm 0.01$ \\
\hline FSn16 & $\begin{array}{c}\text { nanocomposite based on } \\
\text { functionalized } \mathrm{SiO}_{2} \mathrm{SIOX}-5 \mathrm{~S} \\
\text { with nano- } \mathrm{TiO}_{2}(16 \mathrm{wt} \%)\end{array}$ & $0.09 \pm 0.01$ \\
\hline
\end{tabular}
applied on stone

152 To evaluate the morphology of nanoparticles and their distribution in the blends, the nanocomposites were analysed using Transmission Electron Microscopy (TEM, Philips CM200FEG) operated at $200 \mathrm{kV}$. The samples for TEM analyses were prepared by depositing 1 drop of the nanoparticles dispersions onto a carbon coated copper grid of 200 mesh.

156 The nanocomposites were chemically characterized by micro-Fourier Transform Infrared 157 Spectroscopy ( $\mu$-FTIR), using a Nicolet 6700 spectrophotometer coupled with Nicolet Continuum 158 FTIR microscope equipped with an MCT detector (acquired between 4000 and $600 \mathrm{~cm}^{-1}$ with 128 acquisitions and $4 \mathrm{~cm}^{-1}$ resolution), using a micro compression diamond cell accessory. The spectra were baseline corrected using Omnic software. Then, they were normalized on the intensity of the 
Si-O stretching peak, at $1100 \mathrm{~cm}^{-1}$ for polysiloxane-based treatments and at $1050 \mathrm{~cm}^{-1}$ for $\mathrm{SiO}_{2}$ based ones and of the F-C stretching peak at $1200 \mathrm{~cm}^{-1}$ for fluoropolymer-based ones.

The morphology of the stone surfaces before and after the application of the treatments was analyzed by Environmental Scanning Electron Microscopy (ESEM) and EDX analyses (Zeiss EVO 50 EP ESEM, equipped with an Oxford INCA 200 - Pentafet LZ4 spectrometer).

Moreover, Carrara marble specimens either untreated or treated were studied by Atomic Force Microscopy (AFM, Solver Pro, NT-MDT), using a silicon cantilever with a tip (NSG10, NTMDT) with height 14-16 $\mu \mathrm{m}$, tip curvature radius $10 \mathrm{~nm}$ and resonant frequency $140-390 \mathrm{KHz}$ to evaluate their morphology and to assess the roughness of the stone surfaces. Measurements were performed in tapping mode, with 2 scans of the surface ( $1 \mu \mathrm{m} \mathrm{X} 1 \mu \mathrm{m}$ and $0.5 \mu \mathrm{m} \mathrm{X} 0.5 \mu \mathrm{m})$, at $0.6 \mathrm{~Hz}$ scan rate. The acquired images were elaborated with the Nova SPM software (NT-MDT), which provided also the root mean square roughness (nm) values.

The evaluation of the surface colour compatibility of the treatments with the stone was carried out by VIS spectrophotometric measurements, with a Konica Minolta CM-600D instrument with a D65 illuminant at $8^{\circ}$, wavelength range between $360 \mathrm{~nm}$ and $740 \mathrm{~nm}$. Measurements were elaborated according to the CIE L*a*b* standard colour system. 25 measurements were performed on each area and the average results of $\mathrm{L}^{*} \mathrm{a} \mathrm{b}^{*}$ were used to calculate the colour difference $\Delta \mathrm{E}^{*}$ between treated and untreated areas $\left(\Delta \mathrm{E}^{*}=\left[\left(\mathrm{L}_{2}^{*}-\mathrm{L}^{*}\right)^{2}+\left(\mathrm{a}_{2}{ }_{2}-\mathrm{a}^{*}{ }_{1}\right)^{2}+\left(\mathrm{b}^{*}{ }_{2}-\mathrm{b}^{*}{ }_{1}\right)^{2}\right]^{1 / 2}\right)$.

Static contact angle and capillary water absorption tests were performed in room conditions, without exposing the samples to solar lamps or UV light, in order to monitor the wettability changes and water absorption of the stone surfaces after application of the treaments. Static contact angle test was performed on 15 points for each sample, according to UNI standard [39], using an OCA (Optical Contact Angle) 20 PLUS (DataPhysics, Germany), with a drop volume of $5 \mu$, after 10 seconds. Moreover, the capillary water absorption of the stone samples was performed according to UNI standard [40] on 50x50x20 mm samples of Carrara marble before and after the application of the treatments (three samples per treatment). The capillary water absorption value per unit area $\left(\mathrm{Q}_{\mathrm{i}}\right.$, expressed in $\left.\mathrm{mg} / \mathrm{cm}^{2}\right)$ is defined with the expression: $Q_{i}=\left(m_{1}-m_{0}\right) / A * 1000$, where $\mathrm{m}_{\mathrm{i}}$ is the mass (g) of the wet sample at time $t_{i}, m_{0}$ is the mass (g) of the dried sample, $A$ is the surface area $\left(\mathrm{cm}^{2}\right)$ in contact with the water. The samples were weighed at the following time intervals: 10 min, 20 min, 30 min, 60 min, 4 h, 6 h, 24 h, 48 h, 72 h and 96 h. The capillary index (CI) was calculated with the equation: $C I=\int_{t 0}^{t f}\left(Q_{i}\right) d t / Q_{t f} t_{f}$, where $\int_{t 0}^{t f}\left(Q_{i}\right) d t$ is the area under the absorption curve, $Q_{t f}$ is the amount of absorbed water per surface unit at the final time $t_{f}$. The relative capillary index $\left(\mathrm{CI}_{\mathrm{rel}}\right)$ was calculated with the equation: 
$C I_{r e l}=\int_{t 0}^{t f} f\left(Q_{i}\right)_{t r} d t / \int_{t 0}^{t f} f\left(Q_{i}\right)_{n t r} d t$, where $\int_{t 0}^{t f} f\left(Q_{i}\right)_{t r} d t$ is the area under the absorption curve

195

196

197

198

199

200

201

202

203

204

205

206

207

208

209

210

211

212

213

214

215

216

217

218

219

220

221

222

223

224

225

of the treated specimen (tr) and $\int_{t 0}^{t f} f\left(Q_{i}\right)_{n t r} d t$ is the area under the absorption curve of the untreated specimen (ntr). Finally, the absorption coefficient (AC, expressed in $\mathrm{mg} /\left(\mathrm{cm}^{2} \mathrm{~s}^{1 / 2}\right)$ ), which is the slope of the straight part of the absorption curve, was calculated from the expression: $A C=\left(Q_{30}-Q_{0}\right) / \sqrt{t_{30}}$, where $Q_{30}$ is the value of the absorbed water per surface unit at $30 \mathrm{~min}$ and $Q_{0}$ is the intercept of the line in the straight part of the curve.

The photocatalytic activity of the nanocomposites was assessed by means of the decomposition of an organic colorant (rhodamine B, rB) test after indoor exposition of the treated samples in a solar irradiation chamber with a xenon arc lamp source and a cut off filter for wavelengths below 290 nm (Suntest CPS ${ }^{+}$, URAI S.p.A). The rhodamine B water solution $(0.05 \mathrm{~g} / \mathrm{l} \pm 0.005 \mathrm{~g} / \mathrm{l})$ was applied, by using a pipette, on the surface of both untreated and treated samples (1 ml per specimen) then, after drying in room conditions, colorimetric measurements were carried out using the reflectance VIS spectrophotometer (Konica Minolta CM-600D instrument, as described above). The degradation of the applied organic dye was monitored on specimens exposed in a solar irradiation chamber where the irradiance was $765 \mathrm{~W} / \mathrm{m}^{2}$ at the same distance $(20 \mathrm{~cm})$ for all the specimens and the temperature was kept at about $45^{\circ} \mathrm{C}$. The colorimetric measurements were carried out after 15, 30, 60, 90 and 150 minutes of irradiation. Only the chromatic coordinate a* was used to evaluate the photocatalytic discoloration of stain over time $\mathrm{D}^{*}$, by the equation: $\mathrm{D}^{*}=$ $\left(\left|a *(t)-a^{*}(r B)\right| /|a *(r B)-a *(0)| * 100\right.$, where $a^{*}(0)$ and $a^{*}(r B)$ are the average values of chromatic coordinate $\mathrm{a}^{*}$ before and after the application of the stained solution and $\mathrm{a}^{*}(\mathrm{t})$ is the $\mathrm{a}^{*}$ value after t hours of light exposure.

\section{Results and discussion}

\subsection{Characterization of $\mathrm{TiO}_{2}$-based nanocomposites}

In Figure 1 TEM images of the nanocomposites obtained by mixing water dispersion of nano- $\mathrm{TiO}_{2}$ with commercial products (Sn16, Sn28, Sn44, Fn16 and FSn16) are reported. From the images it is possible to notice the presence of nanoparticles as elongated structures whose longest axis measures about $40 \mathrm{~nm}$. No aggregation of nanoparticles occurs in polysiloxanes (Fig.1a, b, c) and functionalized $\mathrm{SiO}_{2}$-based treatments (Fig. 1e), even for higher concentrations (Sn28 and Sn44), confirming the results obtained from water dispersion of nano- $\mathrm{TiO}_{2}$ [34]. $\mathrm{TiO}_{2}$ nanoparticles tend to aggregate, instead, in fluoropolymer-based nanocomposite (Fn16), due to the low affinity between nanoparticles and the water dispersion of fluoropolyethers (Figure 1d). 


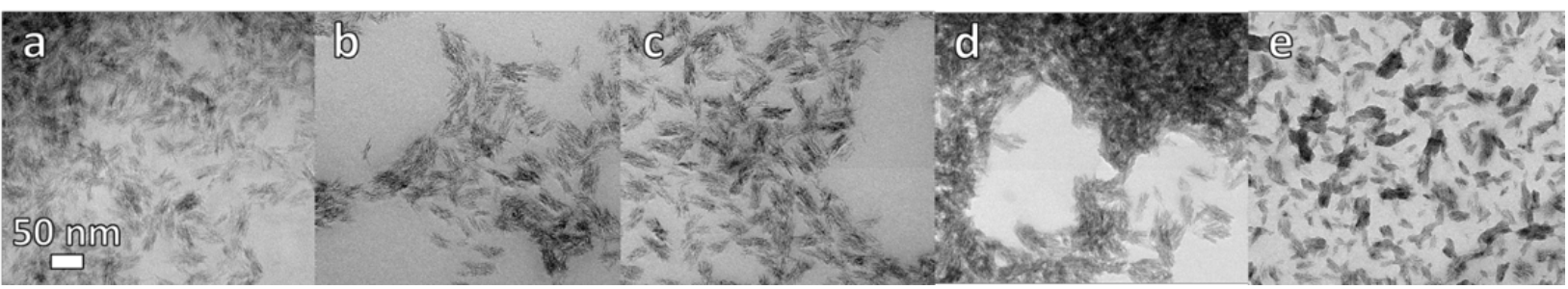

Figure 1. TEM images of the nanocomposites based on polysiloxane: a) Sn16, b) Sn28 and c)

Sn44; on fluoropolyethers: d) Fn16; on functionalized $\mathrm{SiO}_{2}$ : e) FSn16.

The FTIR spectra collected from the polysiloxane-based treatments (S, Sn16, Sn28 and Sn44) are characterized by the typical absorption bands at 1020 and $1100 \mathrm{~cm}^{-1}$ related to Si-O-Si stretching, at $1260 \mathrm{~cm}^{-1}$ (Si-CH bending), at $850 \mathrm{~cm}^{-1}$ (Si-CH 3 rocking) and at about 2950-2850 $\mathrm{cm}^{-1}$ (C-H stretching) (Figure 2a) [16, 41]. By introducing $\mathrm{TiO}_{2}$ nanoparticles in the nanocomposites the following changes in the spectra occur: an increase of the $\mathrm{OH}$ stretching band between 3000-3400 $\mathrm{cm}^{-1}$ and $\mathrm{OH}$ bending band at about $1630 \mathrm{~cm}^{-1}$ due to emisorbed hydroxyls groups bonded to $\mathrm{TiO}_{2}$ and the appearance of the absorption band starting below $700 \mathrm{~cm}^{-1}$ related to Ti-O stretching [34]. The FTIR spectrum of fluoropolyether-based nanocomposite (Fn16) exhibits no relevant difference compared to that of the commercial product (F) and they are both characterized by peaks at about 1200 and $1150 \mathrm{~cm}^{-1}$, arising from $\mathrm{CF}_{2}$ symmetric stretching and at $970 \mathrm{~cm}^{-1}$, related to CO-C symmetric stretching (Figure 2b) [42, 43]. Despite less significant compared to Sn16 and FSn16, a slight increase in the absorption band starting from $700 \mathrm{~cm}^{-1}$ related to $\mathrm{TiO}_{2}$ nanoparticles can be detected in FSn16. The lower intensity of this absorption in Fn16 compared to the other nanocomposites can be probably ascribed to the less homogenous distribution of the nanoparticles in the nanocomposite. As reported in Figure 2c, the spectra from the functionalized- $\mathrm{SiO}_{2}$ treatments (FS and FSn16) show the absorption bands at 1070 and $795 \mathrm{~cm}^{-1}$ assigned to Si-O-Si asymmetric stretching and Si-O-Si symmetric stretching, respectively, which can be ascribed to the silica matrix [16, 42, 43]. Moreover, they have peaks at about $2955-2850 \mathrm{~cm}^{-1}$, related to C-H stretching, a broad band at about $3390 \mathrm{~cm}^{-1}$ and a peak at $1634 \mathrm{~cm}^{-1}$, which are assigned to $\mathrm{OH}$ stretching and bending vibrations, attributed to $\mathrm{Si}-\mathrm{OH}$ groups or water absorbed on nano- $\mathrm{TiO}_{2}$ [44]. In addition, the slight broadening of the peak at about $950 \mathrm{~cm}^{-1}$, attributed to Si-OH vibrations, in the nanocomposite spectrum can be ascribed to the formation of Si-O-Ti interactions between the silica matrix and the nanoparticles [16, 44, 45]. 

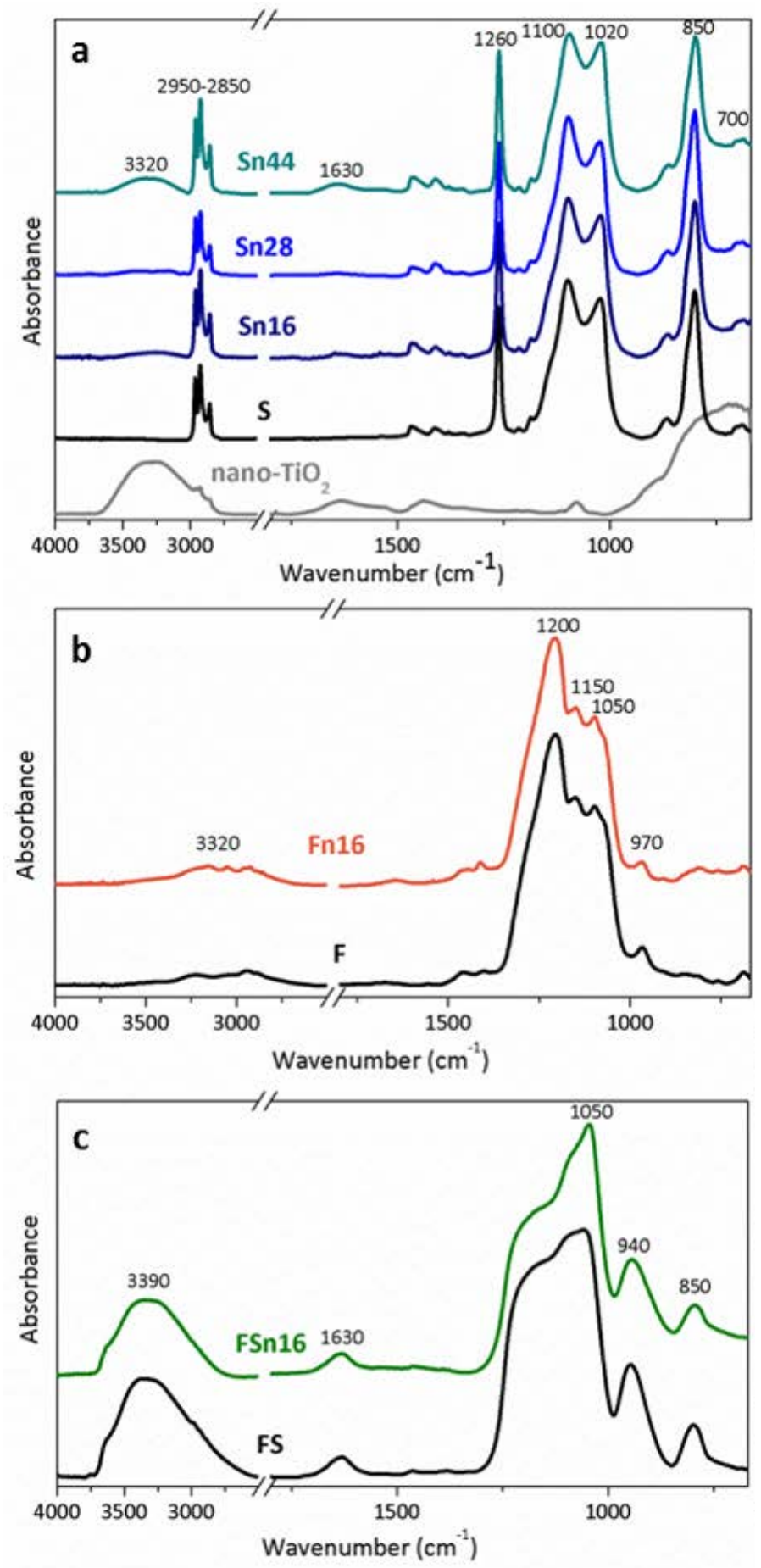

Figure 2. $\mu$-FTIR spectra of: a) water dispersion of nano- $\mathrm{TiO}_{2}$ (3 wt\%), polysiloxane commercial product (S) and polysiloxane-based nanocomposites (Sn16, Sn28, Sn44); b) fluoropolyether commercial product (F) and fluoropolyether-based nanocomposite (Fn16); c) functionalized $\mathrm{SiO}_{2}$ commercial product (FS) and functionalized $\mathrm{SiO}_{2}$-based nanocomposite (FSn16). 
263

264

265

266

267

268

269

270

271

272

273

274

275

276

277

278

279

280

281

282

283

284

285

286

287

288

289

To study the morphology of the protective treatments, ESEM-EDX analyses were carried out on Carrara marble specimens before and after the application of treatments. In the ESEM images, in backscattered electrons, the darker areas on the surface are those where the treatment accumulates, as silicon of the matrix is lighter than calcium of the stone substrate.

Both pure polysiloxane polymer (S, Fig.3b) and polysiloxane-based nanocomposites (Sn16, Sn28 and Sn44, Fig.3e-g, Fig.4a-d) homogenously cover the marble surface with a rather thick layer of product, without creating micro-cracks, which enhances the surface roughness. In particular, the high content of nanoparticles in Sn44 leads to the formation of a porous and sponge-like surface morphology that covers the crystals (Fig.4c-d). In addition, $\mathrm{TiO}_{2}$ nanoparticles do not aggregate in the polysiloxane-based nanocomposites (Sn16, Sn28 and Sn44) and are distributed on the surface in association with the silicon matrix, as shown by the simultaneous presence of $\mathrm{Si}$ and $\mathrm{Ti}$ signals in the same areas in the elemental maps (Fig.3e-g).

Regarding the fluoropolyethers-based products, both the reference polymer (F, Fig.3h) and the nanocomposite (Fn16, Fig.3i) are not homogeneously spread on the stone surface, but they concentrate in micrometric clusters. This behaviour is particularly evident for Fn16, as the blend does not show a good affinity with the calcite surface and it rather forms aggregated structures (Fig.3h, Fig.4e) where the polymer and Ti atoms are concentrated. This is due to the poor ability of the fluoropolymer coatings to adhere to the stone substrate [3].

Finally, a rather good coverage of the marble surface is also achieved by functionalized $\mathrm{SiO}_{2}$ based treatments (FS and FSn16), as reported in Figure 3d and i. This material, in any case, appears different from the linear homogeneous distribution of polysiloxane, forming some small silica aggregates where $\mathrm{Si}$ and $\mathrm{Ti}$ are predominant (Fig.4e). $\mathrm{TiO}_{2}$ nanoparticles are well distributed on the surface as well, as confirmed by EDX map (Fig.3i). 

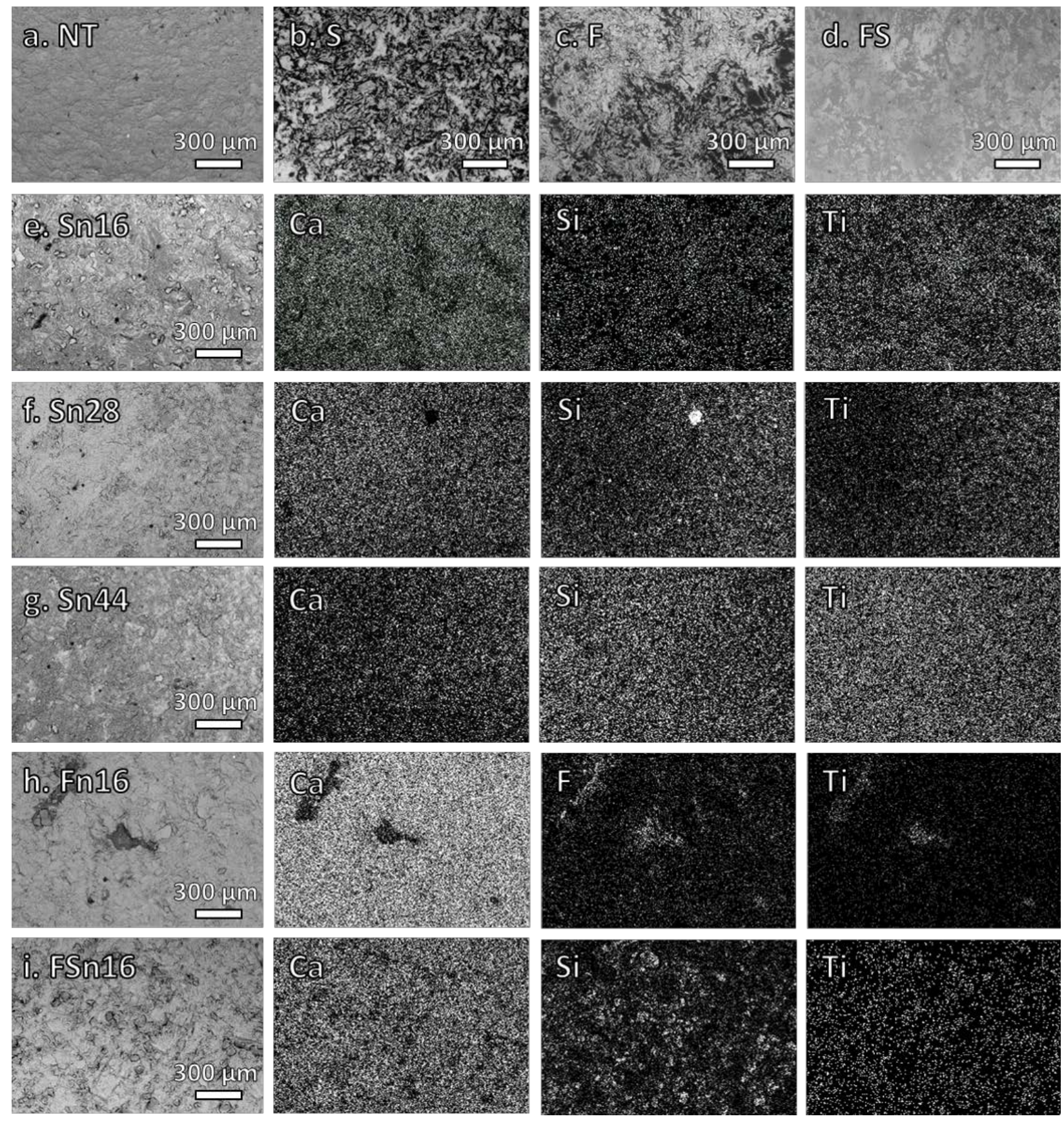

Figure 3. ESEM-EDX images of untreated Carrara marble (a); marble treated with polysiloxane

292 (b), fluoropolyether (c) and functionalized $\mathrm{SiO}_{2}$ (d) commercial products. Marble treated with:

293 Sn18 (e), Sn28 (f) and Sn44 nanocomposite (g) and Ca, Si and Ti maps of distribution; Fn16 nanocomposite (h) and Ca, F and Ti maps of distribution; FSn16 nanocomposite (i) and Ca, Si and 295 Ti maps of distribution. 

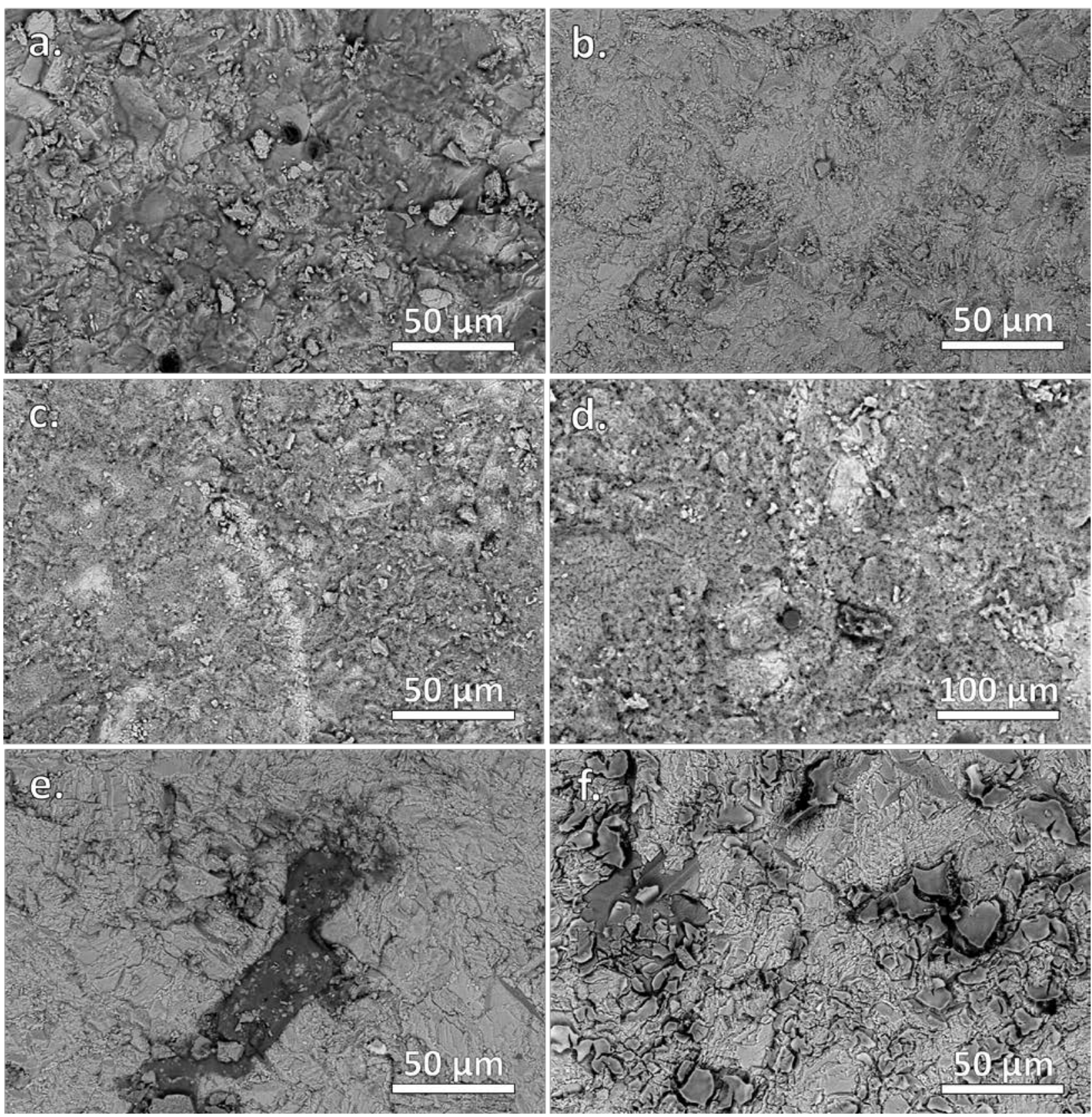

Figure 4. ESEM-EDX images of Carrara marble treated with Sn16 (a), Sn28 (b), Sn44 with a

sponge-like morphology (c, d), Fn16 (e) and FSn16 (f) nanocomposites.

AFM investigations were carried out on Carrara marble specimens both untreated (NT) and treated with the commercial products (F, S and FS) and the nanocomposites (Sn16, Sn28, Sn44, Fn16 and FSn16), in order to study the changes induced to the marble surface topography by the addition of nanoparticles [46]. As reported in Figure 5, compared to both the untreated specimen (NT) and those treated with the pristine polymers (S, F, FS), the nanocomposites are characterized by the presence of new structures that arise from the surface, as shown by the AFM 2D and 3D "height trace” images of the surfaces. 
309 Compared to the untreated specimen (NT), the application of polysiloxane (S) and fluoropolyether

310 (F) products makes the surface smoother (Figure 4), whereas functionalized $\mathrm{SiO}_{2}$ (FS) does not 311 lead to relevant changes of the morphology, probably due to differences in the crystal coverage, 312 as already noted by ESEM analysis. These results are reported in Table 2 where the measured root 313 mean square values of roughness are indicated. Indeed, the values of nanometric roughness 314 obtained from the untreated specimen (NT) are higher than those obtained by S and F, whereas 315 they are very similar to those of FS.

316 An increase of the mean values of nano-roughness is particularly evident for the specimens treated 317 with Sn16, Sn28, Sn44 and Fn16 nanocomposites (Table 2). On the contrary, for those specimens 318 treated with FSn16, some aggregates are formed, showing roughness values which are similar to 319 those obtained from the reference coating (FS) (Figure 5).

320 Moreover, as shown in the AFM 3D and 2D images and in Table 2, by increasing the concentration 321 of $\mathrm{TiO}_{2}$ nanoparticles in the siloxane nanocomposites, a proportional increase of the surface nano322 roughness occurs. This is a positive result, since it significantly influences the wettability of the 323 stone surfaces, as it will be described later. 


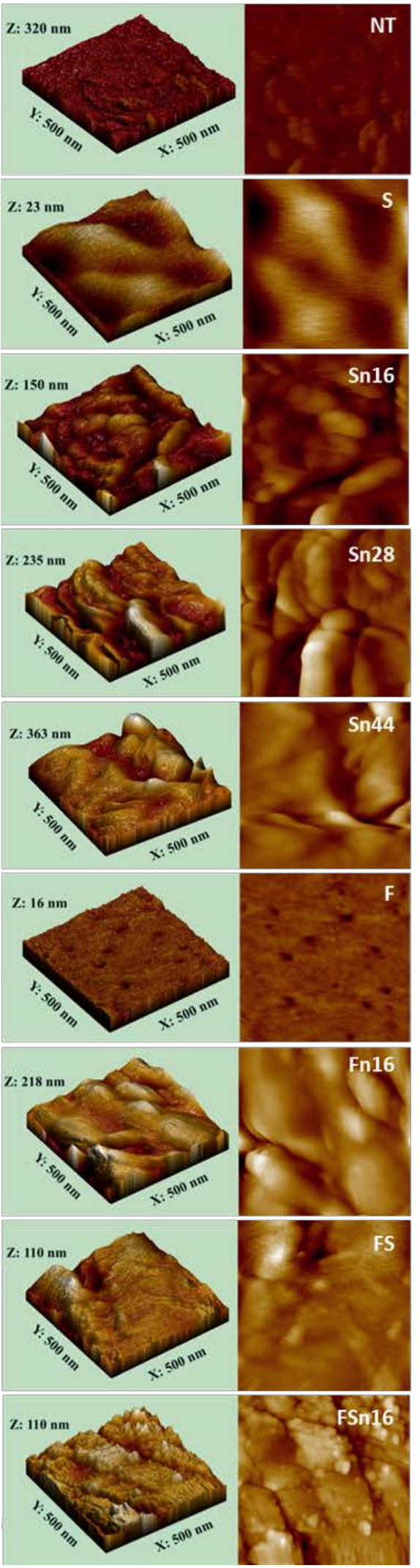

325 Figure 5. From the top to the bottom: AFM 3D and 2D "height trace” image of untreated Carrara 326 marble and treated with the polysiloxane product (S), Sn16, Sn28 and Sn44 nanocomposites, the 327 perfluoropolyether product (F), Fn16 nanocomposite, the functionalized $\mathrm{SiO}_{2}$ product (FS) and 328 FSn16 nanocomposite. 
332

Table 2. Values of root mean square roughness $(\mathrm{nm})$ and static contact angle $\left(^{\circ}\right)$ of both untreated Carrara marble specimens (NT) and treated with the commercial products (S, F and FS) and the nanocomposites (Sn16, Sn28, Sn44, Fn16, FS16).

\begin{tabular}{c|cc} 
& $\begin{array}{c}\text { Root mean square } \\
\text { roughness (nm) }\end{array}$ & $\begin{array}{c}\text { Static contact } \\
\text { angle }\left(^{\circ}\right)\end{array}$ \\
\hline NT & $11.94 \pm 1.19$ & $48 \pm 4$ \\
\hline S & $3.52 \pm 0.35$ & $95 \pm 6$ \\
Sn16 & $18.01 \pm 1.80$ & $129 \pm 5$ \\
Sn28 & $31.39 \pm 3.14$ & $138 \pm 2$ \\
Sn44 & $37.62 \pm 3.76$ & $149 \pm 4$ \\
\hline F & $0.70 \pm 0.07$ & $106 \pm 2$ \\
Fn16 & $24.43 \pm 2.44$ & $136 \pm 5$ \\
\hline FS & $10.21 \pm 1.02$ & $60 \pm 2$ \\
FSn16 & $11.80 \pm 1.18$ & $34 \pm 3$
\end{tabular}

\subsection{Evaluation of the surface colour compatibility of $\mathrm{TiO}_{2}$-based nanocomposites}

In order to verify the fulfilment of the important requirement of surface colour compatibility of the products, spectrophotometric measurements were performed on the specimens before and after the application of the treatments. Table 3 summarizes the values of $\Delta \mathrm{L}^{*}, \Delta \mathrm{a}^{*}, \Delta \mathrm{b}^{*}$ and $\Delta \mathrm{E}^{*}$ of the fluoropolymer (F), polysiloxane (S), functionalized $\mathrm{SiO}_{2}$ (FS) and the nanocomposites (Sn16, $\mathrm{Sn} 28, \mathrm{Sn} 44, \mathrm{Fn} 16, \mathrm{FS} 16)$. The values of $\Delta \mathrm{E}^{*}$ are lower than 4 for each treatment, indicating that they show good colour compatibility with the substrate, as they do not overcome the threshold value of 5 [47]. The application of nanocoatings leads to lower $\Delta \mathrm{E}^{*}$ values compared to the commercial products (, , F and FS). It is worth noting that, among surfaces treated with polysiloxane-based nanocoatings, $\Delta \mathrm{E}^{*}$ values decrease with the increase of the nano- $\mathrm{TiO}_{2}$ concentration, since they exhibit lower differences of $\mathrm{L}^{*}$ and $\mathrm{b}^{*}$ compared to the surface before the application of the treatments. This is due to the whitening effect of nano- $\mathrm{TiO}_{2}$ on the external surface which can balance the slight yellow colour of the polymer, as confirmed also by other researchers [29]. The very low $\Delta \mathrm{E}^{*}$ value obtained by specimen treated with Fn16 could be related to the fact that the product is not well distributed on the surface but it aggregates in small cluster, as shown by ESEM-EDX analysis and previously discussed (Fig.3h). $\Delta \mathrm{E}^{*}$ values lower than 1 were measured from surfaces treated with both the functionalized $\mathrm{SiO}_{2}$-based treatments (FS and FSn16), proving their excellent color compatibility. 
Table 3. $\Delta \mathrm{L}^{*}, \Delta \mathrm{a}^{*}, \Delta \mathrm{b}^{*}$ and $\Delta \mathrm{E}^{*}$ values measured on the specimens before and after the application of 354 the treatments.

355

\begin{tabular}{c|cccc} 
& $\boldsymbol{\Delta} \mathbf{L}^{*}$ & $\mathbf{\Delta} \mathbf{a}^{*}$ & $\boldsymbol{\Delta} \mathbf{b}^{*}$ & $\mathbf{\Delta} \mathbf{E}^{*}$ \\
\hline S & -3.69 & -0.12 & 0.99 & 3.82 \\
Sn16 & -2.56 & -0.10 & 0.72 & 2.66 \\
Sn28 & -1.90 & -0.01 & 0.58 & 1.99 \\
Sn44 & -1.61 & -0.07 & 0.67 & 1.75 \\
\hline F & -1.78 & -0.17 & 2.14 & 2.79 \\
Fn16 & -0.23 & 0.00 & 0.12 & 0.26 \\
\hline FS & -0.80 & -0.04 & 0.07 & 0.80 \\
FSn16 & -0.56 & -0.05 & -0.02 & 0.56
\end{tabular}

\subsection{Evaluation of the wettability and water absorption properties}

As reported in Table 2, the specimens treated with the fluoropolymer and polysiloxane coatings (F and $S$ ) show significantly higher contact angle $\theta$ values compared to the untreated ones, since the polymeric treatments reduce the wettability of the marble surface. Besides that, the specimens treated with the nanocomposites Sn16, Sn28, Sn44 and Fn16 show higher contact angle values than those with the pristine polymers $\mathrm{F}$ and $\mathrm{S}$. This evidence is assigned to the introduction of nanoparticles in the treatments which are able to enhance the surface nano-roughness (Table 2), with the reduction of the surface free energy, as defined by the Cassie equation [48] and reported by other Authors [6, 7, 24, 49]. Different factors influence the wettability of inorganic materials treated with organic compounds (surface substrate morphology, interactions between surface and treatment, distribution and orientation of the hydrophobic alkyl chains of the polymer). Among them, the original morphology of the substrate plays a crucial role, since the presence of microand nano-roughness significantly affect the surface wettability [50, 51]. The results obtained from the addition of $\mathrm{TiO}_{2}$ nanoparticles to $\mathrm{F}$ and $\mathrm{S}$ are in good agreement with the values of nanoroughness measured by AFM investigations (Table 2). In addition, by increasing the nanoparticles concentration in the composites, as in Sn16, Sn28 and Sn44, higher values of contact angles are measured, according to the proportional increase of nano-roughness evidenced by AFM analysis (Table 2). The agreement between these parameters indicates a good correlation between surface wettability and roughness (Figure 6). In particular, the specimen treated with Sn44 shows superhydrophobic features, since it reaches a mean contact angle value of about $150^{\circ}$, surely connected with the surface sponge like nanostructure observed by ESEM (Figure 4).

The specimens treated with functionalized $\mathrm{SiO}_{2}$ (FS) and functionalized $\mathrm{SiO}_{2}$-based nanocomposite (FSn16) show a different behaviour, as they display values of contact angle similar to those obtained by the untreated specimen. This result can be once again correlated to the 
comparable roughness values measured with AFM on specimens either untreated or treated with FS and FSn16 (Fig.6). FS is an inorganic product, with no water repellent properties and it does not affect the hydrophilic properties of the stone. Besides that, the addition of nanoparticles to the nanocomposite provides hydrophilic properties to the surface, since the related specimens show lower contact angle values compared to those treated with FS. This should be ascribed to the behaviour of $\mathrm{TiO}_{2}$ nanoparticles which confer hydrophilic properties when applied as water or solvent dispersions [34] or in the presence of a hydrophilic matrix or binder [48].

It is well known that the capillary water absorption of fresh Carrara marble is rather low and that the protection of such substrate from water income is rather difficult. The efficacy of a treatment is affected by different factors: mineralogical composition and intrinsic wettability of the substrate; finishing and natural roughness; total open porosity and pore size distribution, the penetration depth of the treatment and its ability to cover and adhere to the pore walls [52]. Table 4 reports the values of the parameters that can be obtained by the water absorption by capillarity test, after a prolonged contact of the untreated and treated marble surfaces with water.

The values of capillary index (CI) and absorption coefficient (AC) decrease after the application of all treatments, indicating that a reduction of the water absorption occurs but, as it happens for this kind of compact natural stones, it is a rather modest reduction. The best results and lowest values of relative capillary index $\left(\mathrm{CI}_{\mathrm{rel}}\right)$ are obtained from specimens treated with the nanocomposites, proving the beneficial effect of the addition of nano- $\mathrm{TiO}_{2}$ in the formulation. This behaviour is particularly evident for polysiloxane-based nanocomposites (Sn16, Sn28 and Sn44). Both FS and FSn16 show a rather good protection efficacy and reduce the water absorption by capillarity of about 50\%, although they show a low or negligible water repellency (Table 2 and Figure 6). This result can be probably associated to the fact that both FS and FSn16 are suitable to penetrate inside the few and narrow pores of the marble and cover the crystal grains filling the pores, as observed by ESEM-EDX investigations (Fig.3d and i). In particular, in the specimens treated with FSn16, the $\mathrm{CI}_{\text {rel }}$ value is slightly lower than that obtained from FS, indicating that for this treatment the addition of nanoparticles in the product does not further reduce the water absorption. 
408

409

410

411

412 Table 4. Values of maximal water absorption (Qi) $\left(\mathrm{mg} / \mathrm{cm}^{2}\right)$, capillary index (CI), relative capillary 413 index $\left(\mathrm{CI}_{\mathrm{rel}}\right)$ and absorption coefficient $(\mathrm{AC})\left(\mathrm{mg} / \mathrm{cm}^{2} \mathrm{~s}^{-1 / 2}\right)$ for untreated $(\mathrm{nt})$ and treated ( $\mathrm{t}$ ) Carrara 414 marble specimens.

Figure 6. Correlation between values of static contact angle and root mean square roughness (nm) of the untreated and treated marble specimens.

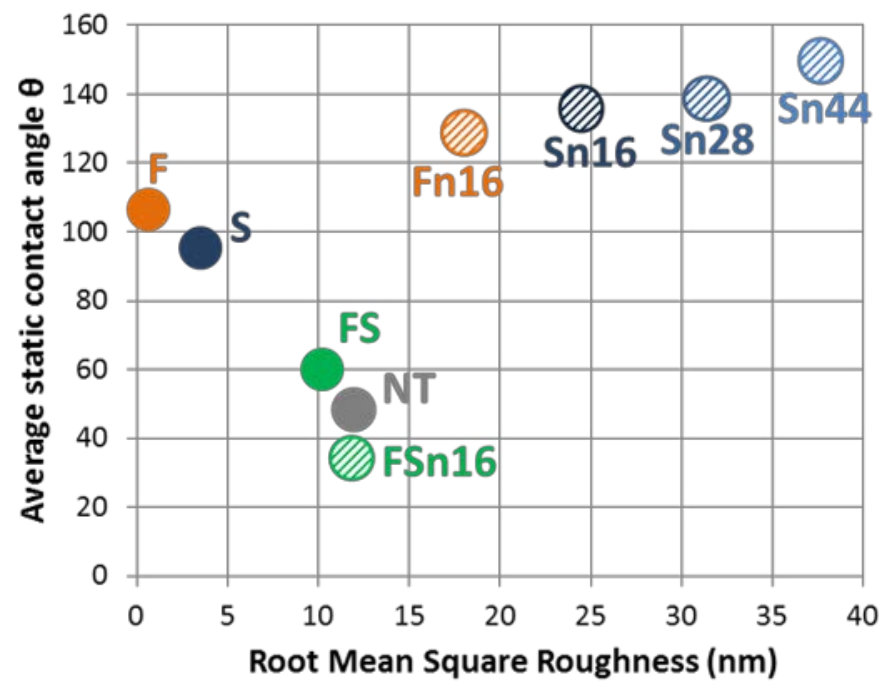

\begin{tabular}{cccccc} 
Treatment & & Qi & CI & CI $_{\text {rel }}$ & AC \\
\hline \multirow{2}{*}{ S } & nt. & $7.12 \pm 1.55$ & $0.90 \pm 0.08$ & \multirow{2}{*}{$0.78 \pm 0.05$} & $0.11 \pm 0.04$ \\
& t. & $5.45 \pm 1.11$ & $0.92 \pm 0.08$ & & $0.03 \pm 0.02$ \\
\hline \multirow{2}{*}{ Sn16 } & nt. & $6.46 \pm 1.24$ & $0.92 \pm 0.09$ & \multirow{2}{*}{$0.55 \pm 0.03$} & $0.08 \pm 0.04$ \\
& t. & $4.37 \pm 0.83$ & $0.71 \pm 0.06$ & & $0.02 \pm 0.01$ \\
\hline \multirow{2}{*}{ Sn28 } & nt. & $7.96 \pm 1.67$ & $0.88 \pm 0.08$ & \multirow{2}{*}{$0.44 \pm 0.07$} & $0.08 \pm 0.04$ \\
& t. & $4.76 \pm 0.86$ & $0.65 \pm 0.07$ & & $0.02 \pm 0.01$ \\
\hline \multirow{2}{*}{ Sn44 } & nt. & $5.46 \pm 0.92$ & $0.89 \pm 0.06$ & \multirow{2}{*}{$0.48 \pm 0.03$} & $0.05 \pm 0.03$ \\
& t. & $3.26 \pm 0.58$ & $0.72 \pm 0.05$ & & $0.02 \pm 0.01$ \\
\hline \multirow{2}{*}{ F } & nt. & $7.99 \pm 1.62$ & $0.92 \pm 0.09$ & \multirow{2}{*}{$0.77 \pm 0.08$} & $0.12 \pm 0.06$ \\
& t. & $7.4 \pm 1.58$ & $0.76 \pm 0.08$ & & $0.01 \pm 0.01$ \\
\hline \multirow{2}{*}{ Fn16 } & nt. & $5.93 \pm 1.13$ & $0.88 \pm 0.09$ & \multirow{2}{*}{$0.73 \pm 0.09$} & $0.06 \pm 0.02$ \\
& t. & $4.25 \pm 1.09$ & $0.9 \pm 0.07$ & & $0.04 \pm 0.02$ \\
\hline \multirow{2}{*}{ FS } & nt. & $6.18 \pm 1.32$ & $0.88 \pm 0.05$ & \multirow{2}{*}{$0.55 \pm 0.04$} & $0.07 \pm 0.03$ \\
& t. & $4.11 \pm 0.98$ & $0.73 \pm 0.05$ & & $0.01 \pm 0.01$ \\
\hline \multirow{2}{*}{ FSn16 } & nt. & $5.7 \pm 0.89$ & $0.9 \pm 0.08$ & & $0.07 \pm 0.02$ \\
& t. & $3.51 \pm 0.83$ & $0.74 \pm 0.07$ & & $0.01 \pm 0.01$
\end{tabular}




\subsection{Evaluation of the photocatalytic activity of $\mathrm{TiO}_{2}$-based nanocomposites}

Figure 7 reports the trend of rhodamine $B$ discoloration $\left(D^{* \%}\right)$ after pre-fixed intervals of exposition to xenon lamp irradiation of Carrara marble specimens both untreated (NT) and treated with the commercial products (S, F and FS) and the nanocomposites (Sn16, Sn28, Sn44, Fn16, FSn16).

The specimens both untreated and treated with the pristine products (S, F and FS) exhibit stain discoloration due to the photolytic and thermal degradation of rhodamine exposed to xenon irradiation. As expected, the specimens treated with the nanocomposites show higher values of stain discoloration, i.e. higher photocatalytic activity, compared to the untreated ones and the commercial products, due to the presence of nano- $\mathrm{TiO}_{2}$, which accelerate the oxidative degradation of the colorant. Among the treatments, the best results in terms of photoactivity are obtained by the siloxane based nanocomposites - Sn16, Sn28 and Sn44 - which reach the maximum value of $90 \%$, whereas fluoropolymer-based treatment obtains $55 \%$ and functionalized $\mathrm{SiO}_{2}$-based one reaches $70 \%$ of stain discoloration. In addition, the polysiloxane-based nanoproducts display a faster stain discoloration rate within the first 15 minutes compared to the other nanocomposites. By comparing nanocomposites with the same nano- $\mathrm{TiO}_{2}$ concentration (Sn16, Fn16 and FSn16), it is evident that Sn16 is more photoactive, most probably due to the availability of nanoparticles well distributed on the marble surface and to the formation of sponge-like surface nanostructure. The poor performance in photoactivity of Fn16 can be ascribed to the scarce surface coverage of the treatment with aggregation of nanoparticles, as reported in ESEM-EDX images and elemental maps (Fig.3h). The poorer effectiveness of FSn16 compared to Sn16 can be attributed to nanoparticles aggregation or to a shield effect of $\mathrm{SiO}_{2}$ matrix surrounding nano- $\mathrm{TiO}_{2}$.

As reported in Figure 7 and Table 5, at increasing values of nano- $\mathrm{TiO}_{2}$ concentration in the polysiloxane-based nanocomposites, a better colorant discoloration is achieved, especially at the beginning of the test. Evidently, in these nanocomposites the highest nanoparticles concentration corresponds to the highest photoactive specific surface. 


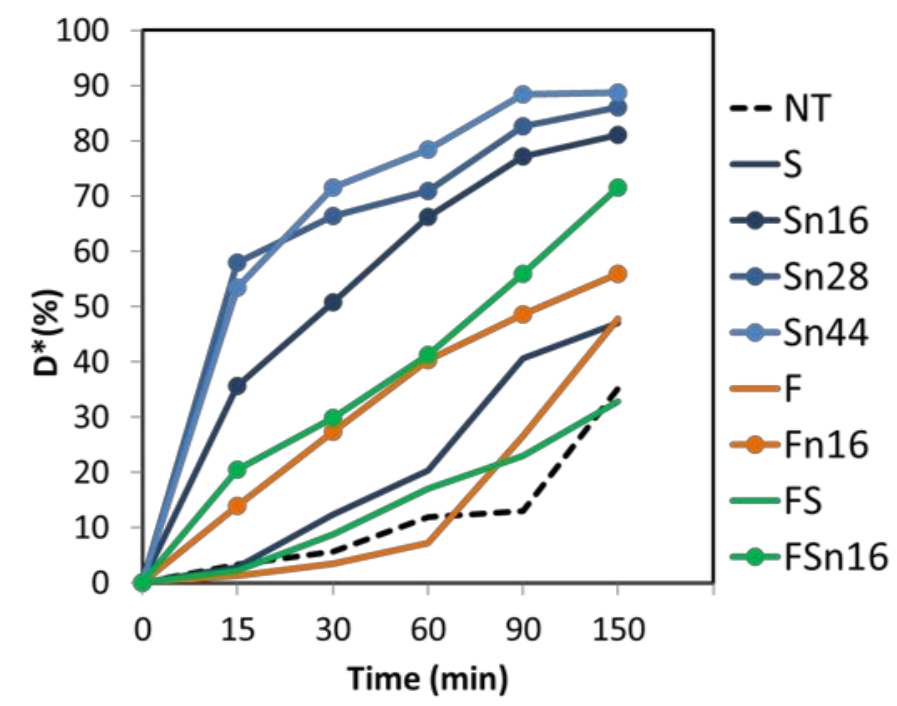

444

445

446

447

448

449

450

451

452

453

454

455

456

457

458

459

460

461

Figure 7. Stain discoloration values $\mathrm{D}^{*}(\%)$ as a function of irradiation time (min.) for Carrara marble either untreated (NT) or treated (S, Sn16, Sn28, Sn44, F, Fn16, FS, FSn16).

Table 5. Ratio between the values of stain discoloration $D^{*}$ of Carrara marble samples treated with the commercial products $(\mathrm{D} * \mathrm{~S}, \mathrm{D} * \mathrm{~F}$ and $\mathrm{D} * \mathrm{FS})$ and the nanocomposites $(\mathrm{D} * \operatorname{Sn} 16, \mathrm{D} * \operatorname{Sn} 28$, D*Sn44, D*Fn16, D*FSn16) and the untreated sample (D*NT).

\begin{tabular}{|c|c|c|c|c|c|c|c|c|}
\hline $\begin{array}{l}\text { Time } \\
\text { (min.) }\end{array}$ & $\begin{array}{c}\text { D*S/ } \\
\text { D*NT }\end{array}$ & $\begin{array}{c}\text { D*Sn16/ } \\
\text { D*NT }\end{array}$ & $\begin{array}{c}\text { D*Sn28/ } \\
\text { D*NT }\end{array}$ & $\begin{array}{c}\text { D*Sn44/ } \\
\text { D*NT }\end{array}$ & $\begin{array}{c}\text { D*F/ } \\
\text { D*NT }\end{array}$ & $\begin{array}{c}\text { D*Fn16/ } \\
\text { D*NT }\end{array}$ & $\begin{array}{l}\text { D*FS/ } \\
\text { D*NT }\end{array}$ & $\begin{array}{c}\text { D*FSn16 } \\
\text { /D*NT }\end{array}$ \\
\hline 15 & 0.85 & 10.73 & 17.42 & 16.06 & 0.37 & 4.19 & 0.69 & 6.17 \\
\hline 30 & 2.20 & 9.02 & 11.78 & 12.70 & 0.63 & 4.87 & 1.56 & 5.29 \\
\hline 60 & 1.71 & 5.56 & 5.95 & 6.59 & 0.61 & 3.38 & 1.44 & 3.46 \\
\hline 90 & 3.14 & 5.96 & 6.38 & 6.83 & 2.05 & 3.75 & 1.78 & 4.32 \\
\hline 150 & 1.34 & 2.31 & 2.45 & 2.53 & 1.36 & 1.59 & 0.94 & 2.04 \\
\hline
\end{tabular}

4. Conclusions

The introduction of innovative nano- $\mathrm{TiO}_{2}$ into commercial protective treatments having different chemical features (organosiloxanes, fluoropolyethers and functionalized $\mathrm{SiO}_{2}$ ) significantly influences their effectiveness once applied on low porosity stone such as Carrara marble, leading to different results depending on the matrix.

Compared to the pristine product, relevant enhancement in the protective action results from the polysiloxane-based nanocomposites (Sn16, Sn28 and Sn44). In particular, by increasing the content of $\mathrm{TiO}_{2}$ nanoparticles in the blend, a sponge-like nanostructure has been formed. This 
morphology grants a better colour compatibility and the prevention of the water uptake by capillarity, increases the water-repellency of the surface due to the enhancement in the nanoroughness and imparts excellent photocatalytic properties. In the case of fluoropolyether, the nanocomposite (Fn16) is not homogenously distributed on the marble surface, leading to poor results in terms of water absorption reduction and photoactivity. By adding nano- $\mathrm{TiO}_{2}$ in the inorganic functionalized $\mathrm{SiO}_{2}$ product, the surface hydrophilic nature of marble is enhanced and FSn16 imparts good reduction of water uptake and photocatalytic properties.

An important parameter to be considered for the optimization of the formulation of polymeric nanocomposites is the chemical stability after ageing, as $\mathrm{TiO}_{2}$ nanoparticles can catalyse the degradation of the polymeric matrix. Accelerated ageing tests will be carried out in order to evaluate how a simulated solar irradiation affects the effectiveness of nanocomposites applied on marble specimens.

The encouraging results so far obtained in lab allowed to test the most promising nanocomposites (Sn44 and FSn16) on-site for the protection of Crevoladossola and Candoglia marbles employed in the façade of the Cathedral of Monza (Italy) [53]. The results of the 1-year on-site monitoring confirmed the good effectiveness of the innovative treatments in terms of aesthetic and protection properties compared to commercial reference products.

\section{Acknowledgements}

The Authors are particularly grateful to Dr. A. Colombo for the development of the nanoparticles dispersions and for the kind advice and suggestions during the experimental work.

\section{References}

[1] A.E. Charola, Water Repellents and Other "Protective" Treatments: A Critical Review, in: Hydrophobe III - 3rd International Conference on Surface Technology with Water Repellent Agents, Aedificatio Publishers, Hannover, 2001.

[2] T. Poli, L. Toniolo, The challenge of protecting outdoor exposed monuments from atmospheric attack: experience and strategy, in: S.K. Kourkoulis (Ed.) Fracture and failure of natural building stones, Springer, Berlin, 2006.

[3] E.F. Doehne, C.A. Price, Stone conservation: an overview of current research, Getty Conservation Institute, Los Angeles, 2010.

[4] I.P. Parkin, R.G. Palgrave, Self-cleaning coatings, Journal of Materials Chemistry, 15 (2005) 16891695.

[5] P.N. Manoudis, I. Karapanagiotis, A. Tsakalof, I. Zuburtikudis, C. Panayiotou, Superhydrophobic composite films produced on various substrates, Langmuir, 24 (2008) 11225-11232.

[6] P.N. Manoudis, I. Karapanagiotis, A. Tsakalof, I. Zuburtikudis, B. Kolinkeová, C. Panayiotou, Superhydrophobic films for the protection of outdoor cultural heritage assets, Appl. Phys. A, 97 (2009) 351-360. 
[7] D.S. Facio, M.J. Mosquera, Simple Strategy for Producing Superhydrophobic Nanocomposite Coatings

[8] G. Soliveri, D. Meroni, G. Cappelletti, R. Annunziata, V. Aina, G. Cerrato, S. Ardizzone, Engineered organic/inorganic hybrids for superhydrophobic coatings by wet and vapour procedures, J Mater Sci, 49 (2014) 2734-2744.

[9] D. Aslanidou, I. Karapanagiotis, C. Panayiotou, Tuning the wetting properties of siloxane-nanoparticle coatings to induce superhydrophobicity and superoleophobicity for stone protection, Materials \& Design, 108 (2016) 736-744.

[10] A. Fujishima, T.N. Rao, D.A. Tryk, Titanium dioxide photocatalysis, Journal of Photochemistry and Photobiology C: Photochemistry Reviews, 1 (2000) 1-21.

[11] A. Fujishima, X. Zhang, D.A. Tryk, TiO2 photocatalysis and related surface phenomena, Surface Science Reports, 63 (2008) 515-582.

[12] J. Chen, C.-s. Poon, Photocatalytic construction and building materials: From fundamentals to applications, Building and Environment, 44 (2009) 1899-1906.

[13] P. Munafò, G.B. Goffredo, E. Quagliarini, $\mathrm{TiO}_{2}$-based nanocoatings for preserving architectural stone surfaces: An overview, Construction and Building Materials, 84 (2015) 201-218.

[14] A. Fujishima, X. Zhang, Titanium dioxide photocatalysis: present situation and future approaches, Comptes Rendus Chimie, 9 (2006) 750-760.

[15] M.F. La Russa, S.A. Ruffolo, N. Rovella, C.M. Belfiore, A.M. Palermo, M.T. Guzzi, G.M. Crisci, Multifunctional TiO2 coatings for Cultural Heritage, Progress in Organic Coatings, 74 (2012) 186-191.

[16] C. Kapridaki, P. Maravelaki-Kalaitzaki, TiO2-SiO2-PDMS nano-composite hydrophobic coating with self-cleaning properties for marble protection, Progress in Organic Coatings, 76 (2013) 400-410.

[17] M.F. La Russa, A. Macchia, S.A. Ruffolo, F. De Leo, M. Barberio, P. Barone, G.M. Crisci, C. Urzì, Testing the antibacterial activity of doped $\mathrm{TiO} 2$ for preventing biodeterioration of cultural heritage building materials, International Biodeterioration \& Biodegradation, 96 (2014) 87-96.

[18] I. Poulios, P. Spathis, A. Grigoriadou, K. Delidou, P. Tsoumparis, Protection of marbles against corrosion and microbial corrosion with TiO2 coatings, Journal of Environmental Science and Health, Part A, 34 (1999) 1455-1471.

[19] A. Licciulli, A. Calia, M. Lettieri, D. Diso, M. Masieri, S. Franza, R. Amadelli, G. Casarano, Photocatalytic TiO2 coatings on limestone, J Sol-Gel Sci Technol, 60 (2011) 437-444.

[20] E. Quagliarini, F. Bondioli, G.B. Goffredo, C. Cordoni, P. Munafò, Self-cleaning and de-polluting stone surfaces: $\mathrm{TiO}_{2}$ nanoparticles for limestone, Construction and Building Materials, 37 (2012) 51-57. [21] L. Pinho, M.J. Mosquera, Titania-Silica Nanocomposite Photocatalysts with Application in Stone SelfCleaning, The Journal of Physical Chemistry C, 115 (2011) 22851-22862.

[22] L. Toniolo, F. Gherardi, The Protection of Marble Surfaces: The Challenge to Develop Suitable Nanostructured Treatments, in: M. Hosseini, I. Karapanagiotis (Eds.) Advanced Materials for the Conservation of Stone, Springer International Publishing, Cham, 2018, pp. 57-78.

[23] F. Gherardi, S. Goidanich, V. Dal Santo, L. Toniolo, Layered nano-TiO2 based treatments for the maintenance of natural stones in historical architecture, Angewandte Chemie International Edition, n/an/a.

[24] P.N. Manoudis, A. Tsakalof, I. Karapanagiotis, I. Zuburtikudis, C. Panayiotou, Fabrication of superhydrophobic surfaces for enhanced stone protection, Surface and Coatings Technology, 203 (2009) 13221328.

[25] C. Kapridaki, P. Maravelaki-Kalaitzaki, $\mathrm{TiO}_{2}-\mathrm{SiO}_{2}-\mathrm{PDMS}$ nano-composite hydrophobic coating with self-cleaning properties for marble protection, Progress Org Coat, 76 (2013).

[26] C. Kapridaki, L. Pinho, M.J. Mosquera, P. Maravelaki-Kalaitzaki, Producing photoactive, transparent and hydrophobic SiO2-crystalline $\mathrm{TiO} 2$ nanocomposites at ambient conditions with application as selfcleaning coatings, Applied Catalysis B: Environmental, 156-157 (2014) 416-427.

[27] G. Cappelletti, P. Fermo, M. Camiloni, Smart hybrid coatings for natural stones conservation, Progress in Organic Coatings, 78 (2015) 511-516.

[28] F. Gherardi, M. Roveri, S. Goidanich, L. Toniolo, Photocatalytic Nanocomposites for the Protection of European Architectural Heritage, Materials, 11 (2018) 65.

[29] D. Colangiuli, A. Calia, N. Bianco, Novel multifunctional coatings with photocatalytic and hydrophobic properties for the preservation of the stone building heritage, Construction and Building Materials, 93 (2015) 189-196. 
[30] M.F. La Russa, N. Rovella, M. Alvarez de Buergo, C.M. Belfiore, A. Pezzino, G.M. Crisci, S.A. Ruffolo, Nano- $\mathrm{TiO}_{2}$ coatings for cultural heritage protection: The role of the binder on hydrophobic and self-cleaning efficacy, Progress in Organic Coatings, 91 (2016) 1-8.

[31] D. Scalarone, M. Lazzari, O. Chiantore, Acrylic protective coatings modified with titanium dioxide nanoparticles: Comparative study of stability under irradiation, Polymer Degradation and Stability, 97 (2012) 2136-2142.

[32] M. Pelaez, N.T. Nolan, S.C. Pillai, M.K. Seery, P. Falaras, A.G. Kontos, P.S.M. Dunlop, J.W.J. Hamilton, J.A. Byrne, K. O'Shea, M.H. Entezari, D.D. Dionysiou, A review on the visible light active titanium dioxide photocatalysts for environmental applications, Applied Catalysis B: Environmental, 125 (2012) 331-349.

[33] A. Colombo, F. Tassone, M. Mauri, D. Salerno, J.K. Delaney, M.R. Palmer, R. Rie, R. Simonutti, Highly transparent nanocomposite films from water-based poly(2-ethyl-2-oxazoline)/TiO2 dispersions, RSC Adv, 2 (2012).

[34] F. Gherardi, A. Colombo, M. D'Arienzo, B. Di Credico, S. Goidanich, F. Morazzoni, R. Simonutti, L. Toniolo, Efficient self-cleaning treatments for built heritage based on highly photo-active and welldispersible TiO2 nanocrystals, Microchemical Journal, 126 (2016) 54-62.

[35] S. Siegesmund, R. Snethlage, Stone in Architecture. Properties, Durability, in, Springer, 2014.

[36] M. Niederberger, M.H. Bartl, G.D. Stucky, Benzyl alcohol and titanium tetrachloride - A versatile reaction system for the nonaqueous and low-temperature preparation of crystalline and luminescent titania nanoparticles, Chemistry of Materials, 14 (2002) 4364-4370.

[37] A. Colombo, F. Gherardi, S. Goidanich, J.K. Delaney, E.R. de la Rie, M.C. Ubaldi, L. Toniolo, R. Simonutti, Highly transparent poly(2-ethyl-2-oxazoline)-TiO2 nanocomposite coatings for the conservation of matte painted artworks, RSC Advances, 5 (2015) 84879-84888.

[38] F. Becherini, G. Pastorelli, G. Valotto, A. Gambirasi, S. Bianchin, M. Favaro, Effects of protective treatments on particle deposition and colour variation in stone surfaces exposed to an urban environment, Progress in Organic Coatings, 112 (2017) 75-85.

[39] EN15802:2009, in, European Committee for Standardization Conservation of cultural property - Test methods - Determination of static contact angle, 2009.

[40] EN15801:2009, in, European Committee for Standardization, Conservation of cultural property - Test methods - Determination of water absorption by capillarity, 2009.

[41] P. Fermo, G. Cappelletti, N. Cozzi, G. Padeletti, S. Kaciulis, M. Brucale, M. Merlini, Hydrophobizing coatings for cultural heritage. A detailed study of resin/stone surface interaction, Applied Physics A: Materials Science and Processing, 116 (2014) 341-348.

[42] G. Legeay, A. Coudreuse, J.-M. Legeais, L. Werner, A. Bulou, J.-Y. Buzaré, J. Emery, G. Silly, AF fluoropolymer for optical use: spectroscopic and surface energystudies; comparison with other fluoropolymers, European Polymer Journal, 34 (1998) 1457-1465.

[43] F.E. Spada, D. Basov, Fourier transform infrared investigation of thin perfluoropolyether films exposed to electric fields, Tribology Letters, 8 (2000) 179-186.

[44] S. Pazokifard, M. Esfandeh, S.M. Mirabedini, M. Mohseni, Z. Ranjbar, Investigating the role of surface treated titanium dioxide nanoparticles on self-cleaning behavior of an acrylic facade coating, $\mathrm{J}$ Coat Technol Res, 10 (2013) 175-187.

[45] F. Milanesi, G. Cappelletti, R. Annunziata, C.L. Bianchi, D. Meroni, S. Ardizzone, Siloxane-TiO2 Hybrid Nanocomposites. The Structure of the Hydrophobic Layer, The Journal of Physical Chemistry C, 114 (2010) 8287-8293.

[46] P. Manoudis, S. Papadopoulou, I. Karapanagiotis, A. Tsakalof, I. Zuburtikudis, C. Panayiotou, Polymer-Silica nanoparticles composite films as protective coatings for stone-based monuments, Journal of Physics: Conference Series, 61 (2007) 1361.

[47] O. García, K. Malaga, Definition of the procedure to determine the suitability and durability of an antigraffiti product for application on cultural heritage porous materials, Journal of Cultural Heritage, 13 (2012) 77-82.

[48] H. Kazuhito, I. Hiroshi, F. Akira, TiO 2 Photocatalysis: A Historical Overview and Future Prospects, Japanese Journal of Applied Physics, 44 (2005) 8269.

[49] I. Karapanagiotis, P.N. Manoudis, A. Savva, C. Panayiotou, Superhydrophobic polymer-particle composite films produced using various particle sizes, Surface and Interface Analysis, 44 (2012) 870-875. 
610 [50] D.M. Spori, T. Drobek, S. Zürcher, M. Ochsner, C. Sprecher, A. Mühlebach, N.D. Spencer, Beyond 611 the Lotus Effect: Roughness Influences on Wetting over a Wide Surface-Energy Range, Langmuir, 24 612 (2008) 5411-5417.

613 [51] D. Quéré, Wetting and Roughness, Annual Review of Materials Research, 38 (2008) 71-99. [52] R. Peruzzi, T. Poli, L. Toniolo, The experimental test for the evaluation of protective treatments: a critical survey of the "capillary absorption index", Journal of Cultural Heritage, 4 (2003) 251-254. [53] F. Gherardi, D. Gulotta, S. Goidanich, A. Colombo, L. Toniolo, On-site monitoring of the performance of innovative treatments for marble conservation in architectural heritage, Heritage Science, 5 (2017) 4. 